\title{
THE EFFECTS OF THE MOTHER HOME-VISIT EDUCATION PROGRAM ON MOTHERS' ATTITUDES AND EMPATHY LEVELS
}

\author{
Ayșe Dilek ÖĞRETí*
}

\author{
Serap DEMIRIZ ${ }^{* *}$
}

ABSTRACT: This research has been performed to examine the effects of the "Mother Home-Visit Education Program on the mother's attitudes and empathy levels of the mothers who have 2-4 years-old children in middle socio-economic levels. The study group has been composed of 110 middle socio-economic level mothers divided into the equal number of experimental (55) and control group (55). The experiment design is based on the pre-test and post-test. Mothers have received 10-weeks the "Mother Home-Visit Education Program." The experimental intervetion aims to measure whether the "Mother Home-Visit Education Program" has an effect on the mothers' positive and negative behaviors by decreasing and increasing them and a change on the mothers' empathy levels. Findings obtained with the "General Knowledge Form" and the "Hammel Mothers Attitudes Scale" and the "Empathic Tendency Scale" which were analyzed by the t-Test. At the end of the research, there was no meaningful differences in the control group mothers. However, the experimental group mothers have exhibited less authoritative, less excessive protective, and less inconsistent behavior attitudes and more democratic attitudes. Moreover, when we compare the control and experimental groups in terms of the empathy levels, the mothers in the experimental group have an increase level of the empathy levels and those in the control group have an decrease level of the empathy levels. As a result, the "Mother Home-Visit Education Program" has effect by increasing the mothers' positive behaviors, decreasing the mothers' negative behaviors, and increasing the mothers' empathy levels.

Key Words:Mother Education, Home-Visit, Mother Attitude

\footnotetext{
* Assist. Prof., Gazi University,Vocational Education Faculty, dilekogretir@ gmail.com

** Assist. Prof.,Gazi University,Vocational Education Faculty, demiriz@ gazi.edu.tr
} 


\section{SUMMARY}

Purpose and Significance: During a child's early years of the development, it is very important the children to have a positive communication with their families especially with their mothers to have a good development. The researchers and theorists have suggested that there is a strong relationship between the parental attitudes and the children's behaviors. The parents who have excessively oppressive, strict, punitive, conditionally loving, and repudiative behaviors can be categorized as authoritive. It is determined that the children who are exposed these behaviors have negative behaviors such as fear and aggression. The uncontrollable and careless behaviors of the parents and damaged communication within the family have determined the children behaviors. The parents who show empathy, affection, love, respect toward their children can be categorized as democratic. The parents who both have democratic attitudes and high empathy levels toward their children have produced creativity and responsibility in their children and increased the self-respect of their children. (Richter, 1985; Craig ve Kermis, 1995; Pardeck ve Pardeck, 1989; Bayraktar, 1998).

Methods: The population of the study was the mothers who have 2-4 years old children and middle socio-economic development level at the city center of Ankara. The researchers have selected the mothers via random sampling. They announced the mother education program to the mothers who have 2-4 years old children in the pre-school classes. They determined the volunteer mothers that were divided into 55 experimental and 55 control groups within the total of 110 mothers. The mothers who belong to the experimental group has received 45 minutes visit during the 10 week period. In the first visit, the aims and expectations of the education program has been explained and the pre-test was performed. At the last visit, the mothers have been interviewed about the positive and negative contributions of the program and they were received the post-test questionnaire. In this research, the mothers have received an experimental condition that increased their democratic attitudes and empathy levels via an education program. This program was tested with the experimental and control groups and pre-test and post-test measurements. In the experimental group, the mothers have received the education program that increased their democratic attitudes and the empathy levels toward their children. The control group have received 45 minutes "environmental pollution" education program once a month and the total of 3 times. The data collection tools were "Personel information form" that collect personnel information about the mothers, the "Hammel Mother Attitude Test" that measures the parents' attitudes toward their children and the "Empathy Level Scale" that measures empathy levels of the mothers toward their children. The results were analyzed by percentage and t-test.

Results: The results have showed that the mothers who in the control group had no significant differences on the measurement tools. The mothers who in the control group had less authoritative, excessively protective and incoherent attitudes and more democratic attitudes. In addition, when the empathy levels of the mothers both in the control and experimental group were compared, the control group had no increase on the empathy level but the experimental group had significant increase on the empathy level.

As a result, the "Mother Home Visit Education Program" had effects on the mothers by increasing their positive behaviors, decreasing their negative behaviors and the increasing the empathy levels. 


\title{
ANNE EV ZIYYRETI EĞİTIM PROGRAMININ ANNELERIN TUTUMLARINA VE EMPATIK EĞILIMLERINE ETKİSi
}

\author{
Ayşe Dilek ÖĞRETíR* $\quad$ Serap DEMİRIZ ${ }^{* *}$
}

ÖZ. Araştırma, 2-4 yaşları arasında çocuğu olan orta sosyoekonomik düzeydeki annelerin anne tutumlarına ve empatik eğilim düzeylerine "Anne Ev Ziyareti Eğitim Programı" nın etkisinin incelenmesi amacıyla yapılmıştır. Çalışmaya orta sosyo ekonomik düzeyde olan 55 deney, 55 kontrol olmak üzere toplam 110 anne katılmıștır. Ön-test ve son-test ölçümlü deneysel bir desen kullanılmıştır. Annelere 10 hafta "Anne Ev Ziyareti Eğitim Programı" uygulanmıştır. Uygulanan "Anne Ev Ziyareti Eğitim Programı" ile annelerin olumlu ve olumsuz davranışlarının sayısının artıp azalmadığı ve empatik eğilim düzeylerini değişip değişmediği deneysel olarak incelenmiştir. Çocukların annelerine uygulanan "Kişisel Bilgi Formu", "Hammel Anne Tutum Testi" ve "Empatik Eğilim Ölçeği" ile elde edilen veriler yüzde oranları ve t-Testi kullanılarak değerlendirilmiştir. Programa katılan kontrol grubundaki annelerin çocuklarına gösterdikleri davranışları incelendiğinde, önemli bir farklılık görülmezken, deney grubundaki annelerin otoriter, aşırı koruyucu ve tutarsız tutumlarının azaldığı, demokratik tutumun arttı̆̆ belirlenmiştir. Ayrıca empatik eğilim düzeyleri açısından kontrol ve deney grubundaki anneler karşılaştıııldığında, kontrol grubundaki annelerde empati düzeyinde önemli bir artış görülmezken deney grubundaki annelerde anlamlı bir artış bulunmuştur. Sonuç olarak uygulanan "Anne Ev Ziyareti Eğitim Programı"nın annelerin demokratik tutumunu artırmada, otoriter, aşırı koruyucu, tutarsız tutumları azaltmada ve empatik eğilim düzeylerini olumlu yönde artırmada etkili olduğu anlaşılmaktadır.

Anahtar Sözcükler: Anne Eğitimi, Ev Ziyareti, Anne Tutumu

\footnotetext{
*Yrd. Doç. Dr., Gazi Üniversitesi Mesleki Eğitim Fakültesi,Çocuk Gelişimi Eğitimi Bölümü, Çocuk Gelişimi ve Eğitimi ABD, ogretir@gazi.edu.tr. dilekogretir@gmail.com

${ }_{* * *}^{*}$ Yrd.Doç.Dr.,Serap DEMIRIZ,Gazi Üniversitesi Mesleki Eğitim Fakültesi, Çocuk Gelişimi Eğitimi Bölümü,Okul Öncesi Eğitimi ABD, demiriz@gazi.edu.tr
} 


\section{GİRiș}

Anne baba tutumları ve sonuçlarını birçok kuramcı incelemiștir. Psikodinamik modelde gelişimin temel belirleyicilerinin biyolojik olduğu ve anne babanın istekleri ile toplumsal beklentiler arasındaki çatışmanın kaçınılmaz olduğu belirtilmiştir.Araştırmacılar, Anne-baba tutumlarındaki farklılıklar, anne-baba ile çocuk arasındaki duygusal ilişkinin bir aileden diğerine gösterdiği bireysel farklılıklar, bağlanmaktadır (Darling ve Steinberg, 1993).

Davranışçılar, yakın çevreden alınan pekiştirecin çocuğun gelişimini nasıl şekillendirdiği ile ilgilenmişler ve davranışın tutumdan daha önemli olduğunu belirtmişlerdir. Çocuğun gelişimindeki bireysel farklılıkların çocuğun içinde bulunduğu öğrenme çevresindeki farklılıkları yansıttığı düşünüldüğü için, davranışçılara göre anne-baba tutumu bu çevreyi tanımlayan davranış örüntüleridir.

Hem psikodinamik hem de davranış̧̧1 model, çocuğun sosyalleşmesinde, anne-babanın inançlarının ve çocuğun doğasının annebaba davranışlarının en önemli belirleyicileri olduğu görüşündedirler (Darling ve Steinberg, 1993 Engler,1981).

Anne babalar çocuklarını yetiştirirken çeşitli yöntem ve metotlar kullanmaktadırlar. $\mathrm{Bu}$ metotlar çocuğa ve çocuğun o anda sergilediği davranışa göre değişim göstermektedir. Anne babalar çocuklarının kendi kendini kontrol etme becerisini geliştirmeyi amaçlar diğer taraftan kendi başına karar vermesini kısıtlayıcı davranışlar sergilerler. Bu çelişki içinde kalan anne baba çeşitli davranış biçimlerinin yoğun olarak yaşanması ile farklı gruplaşmalara yol açmaktadır. Bunları farklı kategoride incelemek mümkündür (Ryder, 1995; Craig ve Kermis, 1995). Anne babanın çocuğunu sosyalleştirmek için kullandığı yöntemler, seçtiği ödül ve cezalar, öğretme biçimleri, aktarmaya çalıştığı değerler, çocukların ilgileri ve sosyal becerileriyle birbirinden farklı kişilikler geliştirmesine neden olur (Maccoby, 1984).

Birçok anne-baba eğer çocuk zorlanmazsa iyi eğitim verilemez düşüncesindedir. Oysa anne-babalar davranışları ile çocuklarına modeldirler. Eğer çocuklarına değer verirlerse, onlara karşı açık olurlarsa, çocuklarının duygularını paylaşırlarsa, kendi duygularını çocukları ile paylaşırlarsa, çocuklarını oldukları gibi kabul ederlerse, yetenekleri doğrultusunda gelişmelerine olanak sağlarlarsa ve çocuklarının yapmak istemediklerini kendileri yapmazsa, çocuklarıda daha sonraki yıllarda diğer bireylerle kurdukları ilişkilerde bu tarzda davranırlar. Anne babalar bu tarzda davranışları ile hem çocuklarının kişilik gelişimine olumlu etkide 
bulunurken olurlar hem de olumlu birer model olurlar (Tausch,1991; Gramer, 1994; Rosenthal, 1994 Geçtan,1981).

Baumrind (1972) anne baba tutumları ile ilgili olarak yaptığı çalışmalarında genel olarak demokratik tutumu benimseyen anne babaların çocuklarının bağımsız, kendini iyi ifade edebilen, hem sosyal hem de akademik yönden başarılı çocuklar olduğunu belirtmiştir.

Çocuk yetiştirmede anne baba tutumları kadar empatik eğilimleri de önemlidir.Rogers empatiyi, "kendini kaybetmeksizin karşıdaki kişinin iç dünyasında olanları anlamak" olarak tanımlamaktadır(White,1997). Empatik eğilim, empatinin duygusal boyutunu oluşturmakta ve bireyin empati yapma potansiyelini göstermektedir. Rogers "Yeni İnsan" adlı kitabında devamlı olarak birine içini döktügünde gözlerinin yaşlarla dolduğunu belirtmektedir. "Bir insan beni dinledi, anladı, biri ben olduğumu gördü, biliyor" diye düşünür. Bu durum mutlu edici bir duygunun oluşmasına neden olmaktadır (Höder,1992).

Rogers'a göre "Gerçek", bireyin algıladığı şekildir. Bireyin davranışlarının, tepkilerinin çıkış noktası kendi iç dünyasıdır. Bireyin iç dünyasını, kendi yaşantıları, duyguları oluşturur ve sadece kendisi bu yaşantıların, duyguların farkındadır. Sadece bireyin kendisi, ne algıladığını, ne yaşadığını, ne hissettiğini söyleyebilir. Buradan şu sonuç çıkarılabilir, her bireyin dünyası farklıdır(Tausch ve Tausch, 1981).

Bireyler çevrelerini nasıl algıliyorsa ona göre davranırlar. Algılanan çevre, birey için gerçek çevredir. Herkes için gerçek "kendine özgüdür". Bireylerin birbirinden farklı tepkiler göstermeleri, çevrelerini farklı olarak algılamaları, farklı kişilik ve benlik sahibi olmalarındandır (Rogers, 1959; Arkonaç, 1998; Kulaksızoğlu, 1999; Aytaç, 2000).

Rogers iki gereksinime, olumlu saygı ve olumlu benlik saygısına ayrı önem verir. Olumlu saygı, bireyin başkaları tarafindan kabul edilmesi, sevilmesi sayg1 görmesi gibi yaşantıları yansıtır. $\mathrm{Bu}$ tür yaşantılara sahip olan kimse, kendisine de saygı duyar. Olumlu benlik saygısı ise başkalarının tutumuna bağlı olmadan, bireyin kendi benliğine karşı olan tutumudur. $\mathrm{Bu}$ gereksinimlerin her ikisi de bebeklikten itibaren kazanılır. Özellikle sevgi konusunda ilk doyum kaynağı annedir (Rogers, 1959).

Sonuç olarak araştırmacılar ve kuramcılar anne baba tutumlarıla çocukların davranışları arasında sıkı bir bağlantı olduğunu savunmuşlardır. Aşırı baskıcı, sert davranan, cezalandıran, şartlı sevgi sunan, reddeden davranışlara sahip anne babalar otoriter olarak nitelendirilmiş̧lerdir. $\mathrm{Bu}$ davranışlara maruz kalan çocuklarda korku, saldırganlık gibi olumsuz 
davranışlar saptanmıştır. Dolayısıyla anne babanın düşüncesiz ve kontrolsüz davranışlarından ileri gelen aile içindeki bozuk iletişim çocuğun davranışlarında belirleyici olabilmektedir. Çocuğu ile empati kuran, ilgi, sevgi dolu, onun kararlarına saygılı olmak gibi olumlu davranışlar sergileyen anne babalar demokratik olarak nitelendirilmişlerdir. Hem demokratik tutumu benimseyen hem de çocuğuyla empati kurabilen anne babaların bu davranışlarının çocuk üzerinde yaratıcılık, sorumluluk taşıma duygusu, kendine güven şeklinde yansıdığı bir çok görüşün ortak noktasıdır (Richter, 1985; Craig ve Kermis, 1995; Pardeck ve Pardeck, 1989; Bayraktar, 1998).

Bu çalışma, 2-4 yaşları arasında çocuğu olan annelerin anne tutumlarına ve empatik eğilim düzeylerine“Anne Ev Ziyareti Eğitim Programı" nın etkisini incelenmek amacıyla planlanarak yapılmıştır.

\section{YÖNTEM}

\section{Araştırmanın Modeli}

$\mathrm{Bu}$ araştırmada, annelerin demokratik tutum ve çocuğu ile empatik eğilim düzeylerini geliştirmesine yönelik eğitim programı hazırlayarak, bu programın etkinliğini belirlemeyi amaçlayan, deney-kontrol gruplu, ön-test ve son-test ölçümlü deneysel bir desen kullanılmıştır.

\section{Çalışma Grubu ve Uygulama}

Ankara il merkezinde 2-4 yaşları arasında çocuğu olan orta-sosyo ekonomik düzeydeki anneler araştırmanın evrenini oluşturmaktadır. Araştırmacılar tarafından tesadüfî örnekleme yöntemiyle seçilen anasınıflarına gidilerek veli toplantılarında 2-4 yaş arası çocuğu olan annelere, ev ziyareti şeklinde anne eğitim programı verileceği duyurulmuş, gönüllü olan anneler belirlenmiştir.Bu annelerin içerisinden tesadüfî yöntemle 55'i deney, 55'i kontrol grubu olmak üzere toplam 110 anne araştırmanın örneklemini oluşturmuştur. Deney grubundaki her annenin evine haftada bir kez $45 \mathrm{dk}$ olmak üzere 10 hafta gidilmiştir. İlk oturumda programın amacı ve beklentiler konuşulmuş ön testler uygulanmıştır. Son oturumda ise bu programın kendilerine olumlu veya olumsuz tüm katkılarını sözel olarak ifade etmeleri istenmiş ve son testler uygulanmıştır.

Deney grubundaki annelere demokratik tutum ve çocuğu ile empatik eğilim düzeylerini geliştirmesine yönelik eğitim programı uygulanırken kontrol grubundaki annelere ayda bir defa $45 \mathrm{dk}$ süren toplam üç kez anne eğitim programılla ilgisi olmayan "çevre kirliliğini” içeren görüşmeler yapılmıştır. 
Çalışmanın bağımsız değişkeni annelerin demokratik tutum ve çocuğu ile empatik eğilim düzeylerini geliştiren eğitim programıdır. Bağımlı değişkenleri ise annenin çocuğuna karşı tutumu ve empatik eğilimleridir.

Anne Eğitim Programı: Deney grubundaki annelerin çocuklarının gelişimleri hakkında bilgilendirilmesi ve çocuklarıyla etkileşimlerinin artırılması amaciyla "Anne Ev Ziyareti Eğitim Programı" hazırlanmıştır. Programda; anne baba tutumları ve çocuk üzerindeki etkileri, çocuğu etkili dinleme ve çocukla konuşma, çocukla iletişim ve empati, sağlıksız iletişim kurmanın çocuk üzerindeki etkileri, çocukla oyun ve cinsel eğitim, konularına yer verilmiştir. Program annelere araştırmacılar tarafından ev ziyareti yöntemi ile uygulanmıştır. Ziyaret iki aşamadan oluşmuştur. Birinci aşamada anneler ile programda yer alan konularda sohbet edilmiş, ikinci aşamada anneye evde çocuğuyla bir hafta boyunca oynayabileceği oyunlar öğretilmiştir. Anneler evde toplam 10 hafta ziyaret edilmiştir. Ev ziyaretleri, anneler ile 25 dakika anne eğitimci sohbeti, 20 dakika oyunların öğretilmesi olmak üzere toplam 45 dakika sürmüştür. Eğitim prgramı deney grubundaki toplam 55 anneye uygulanmıştır.

\section{Veri Toplama Araçları}

$\mathrm{Bu}$ araştırmada annelerin çocuklarına olan tutumunu belirlemek için "Hammel Anne Tutum Testi" ve annelerin empatik eğilimlerini değerlendirmek için "Empatik Eğilim Ölçeği”, kullanılmıştır. Anneler hakkında bilgi toplamak için ise "Kişisel Bilgi Formu" hazırlanmıştır.

Hamel Anne Tutum Testi (Hamburger Erziehungsverhaltensliste Für Mütter), Baumgärtel (1979) tarafindan geliştirilmiş olup, Bonn Üniversitesi Psikoloji Bölüm Başkanı Prof. Dr. Dumke tarafindan, Almanya'da yaşayan yabancı annelere uygulanmıştır. Prof. Dr. Özdoğan tarafindan Türkçe’ye uyarlanmış, Öğretir tarafından ise testin geçerlik güvenirlik çalışması yapılarak Türk kültürüne kazandırılmıştır (Öğretir,2004).

Hamel Anne Tutum Testi, annelerin çocuklarına yönelik davranışlarını "Destek", "Baskı" ve "Aşırı İlgi" alt boyutlarında inceleyen 24 sorudan oluşmaktadır. Annelerden sorulara cevap verirken son dört hafta içinde çocuğuna nasıl davrandığını dikkate alarak, bu davranış ifadelerinden hangisini, ne sıklıkla yaptıklarını işaretlemeleri istenmiştir (Baumgärtel, 1979).

Hamel Anne Tutum Testi, annelerin çocuğuna olan davranışlarını mümkün olabilen en objektif biçimde tanımlamak için kullanılmaktadır. Ayrıca, 5., 9., 12., 15., 20.ve 22. sorular çocukların akademik başarıları ilgili davranışları ölçmektedir. Okul öncesi çocuklarının annelerinin çocuklarına 
olan davranışları 18 soru içinde değerlendirilmektedir. Toplam puanlar ile annenin çocuğuna olan tutumu üç farklı (Destek, Baskı, Aşırı İlgi) tutumdan birisini oluşturmaktadır (Baumgärtel, 1979). Empatik Eğilim Ölçeği (EEÖ) bireylerin günlük yaşamdaki empati kurma potansiyellerini ölçmek amaciyla Dökmen (1987) tarafından geliştirilmiştir. Likert tipli bir ölçek olup, 20 sorudan oluşmaktadır. Alınan toplam puan deneklerin empatik eğilim puanlarını ifade etmektedir. Puanın yüksek olması, empatik eğilimin yüksek olduğunu; düşük olması empatik eğilimin düşük olduğunu gösterir. Ölçeğin araştırma grubu için Cronbach Alpha ile hesaplanan güvenirlik katsayısı .72 olarak bulunmuştur (Dökmen,1994).

\section{Verilerin Analizi}

Veriler bilgisayarda veri tabanı oluşturulduktan sonra, yüzde oranları ve $\mathrm{t}$ testi kullanılarak istatistik işlemler yapılmıştır.

\section{BULGULAR}

2-4 yaşları arasında çocuğu olan annelerin anne tutumlarına ve empatik eğilim düzeylerine“Anne Ev Ziyareti Eğitim Programı" nın etkisini incelemek amacıyla yapılan bu çalışmaya, 110 anne katılmıştır. Katılan annelerin 25-38 yaş aralığında olduğu, \%90'nın ev hanımı olduğu belirlenmiştir. Deney grubundaki annelerin \%54,5'inin kı, \%45,5'inin erkek, kontrol grubundaki annelerin \%49'unun kı, \%50,9'unun erkek çocuğuna sahip olduğu belirlenmiştir.

Tablo 1. Hamel anne tutum testinin deney ve kontrol gruplarına göre ön test ve son test ortalama puanların $t$-testi sonuçlart

\begin{tabular}{|c|c|c|c|c|c|c|c|c|}
\hline $\begin{array}{l}\text { Hamel } \\
\text { Testinin }\end{array}$ & $\begin{array}{l}\text { Anne Tutum } \\
\text { Alt Boyutları }\end{array}$ & $\begin{array}{l}\text { Ön test } \\
\bar{x}\end{array}$ & Ss & $\begin{array}{l}\text { Son test } \\
-- \\
\mathrm{x}\end{array}$ & Ss & $\mathrm{sd}$ & $\mathrm{t}$ & $\mathrm{P}$ \\
\hline $\mathrm{D}$ & Otoriter & 30,63 & 6,01 & 24,25 & 5,31 & 54 & 12,47 & ,000 \\
\hline $\begin{array}{l}E \\
N\end{array}$ & Demokratik & 22,61 & 3,53 & 27,94 & 2,52 & 54 & $-14,40$ & ,000 \\
\hline $\begin{array}{l}E \\
Y \\
(n: 55)\end{array}$ & $\begin{array}{l}\text { Aşırı } \\
\text { Koruyucu } \\
\text { Tutarsız }\end{array}$ & 13,61 & 2,95 & 10,92 & 2,51 & 54 & 8,12 &, 000 \\
\hline $\begin{array}{l}\mathrm{K} \\
\mathrm{O}\end{array}$ & Otoriter & 30,69 & 7,53 & 31,07 & 6,13 & 54 &,- 49 & ,623 \\
\hline $\begin{array}{l}\mathrm{N} \\
\mathrm{T}\end{array}$ & Demokratik & 26,27 & 3,72 & 26,01 & 3,73 & 54 & ,71 & ,477 \\
\hline $\begin{array}{l}\mathrm{R} \\
\mathrm{O}\end{array}$ & $\begin{array}{l}\text { Aşırı } \\
\text { Koruyucu }\end{array}$ & 12,90 & 2,90 & 12,60 & 2,92 & 54 & 1,00 &, 320 \\
\hline $\begin{array}{l}\mathrm{L} \\
(\mathrm{n}: 55)\end{array}$ & Tutarsız & 5,74 & 2,56 & 5,89 & 2,94 & 54 &,- 531 &, 598 \\
\hline
\end{tabular}

$\mathrm{p}<0,001$ 
Tablo 1. incelendiğinde, deney grubunda yer alan annelerin otoriter tutumdaki puanlarının ortalaması ön testte 30,63 son testte 24,25 iken kontrol grubunda yer alan annelerin ön testte 30,69 son testte 31,07 olduğu anlaşılmaktadır. Deney grubunda yer alan annelerin demokratik tutumdaki puanlarının ortalaması ön testte 22,61 son testte 27,94 iken kontrol grubunda yer alan annelerin ön testte 26,27 son testte 26,01 olduğu anlaşılmaktadır. Deney grubunda yer alan annelerin aşırı koruyucu tutumdaki puanlarının ortalamas1 ön testte 13,61 son testte 10,92 iken kontrol grubunda yer alan annelerin ön testte 12,90 son testte 12,60 olduğu anlaş1lmaktadır. Deney grubunda yer alan annelerin tutarsız tutumdaki puanlarının ortalaması ön testte 5,29 son testte 4,00 iken kontrol grubunda yer alan annelerin ön testte 5,74 son testte 5,89 olduğu görülmektedir.

Bu bulgulardan anlaşıldığı gibi “Anne Ev Ziyareti Eğitim Programı”na katılan annelerin son test Hamel Anne Tutum puanları programa katılmayan annelerin son test puanlarından anlamlı düzeyde demokratik tutumda daha yüksek, otoriter, aşırı koruyucu ve tutarsız tutumlarda daha düşük olduğu anlaşılmaktadır. Deney grubundaki annelerin ön test ve son test puanları arasında anlamlı bir fark olduğu görülmektedir $(p<0,001)$.

Kaya'nın (1994) üç-altı yaş arası çocukları olan annelerine sekiz hafta süre ile eğitim vermiş, verilen eğitimin sonucunda annelerin çocuklarına yönelik istenmedik tutumlarının istendik yönde değişip değişmediğini incelemiştir. Sonuçta eğitime katılan anneler ile katılmayan anne gruplarının puan ortalamaları arasında anlamlı bir fark bulunmuştur. Eğitim alan annelerin istenmedik tutum puanlarında eğitim almayan annelere oranla daha fazla düşüş olduğu görülmüştür. $\mathrm{Bu}$ sonuç, araştırma bulguları ile uyuşmaktadır.

Temel (1999) araştırmasında anne eğitim programının ailelerin tutumlarına etkisini incelemiştir. Araştırmanın sonucunda deney grubunda ön test son test arasında olumlu gelişmeler bulmuştur.

Programa katılan annelerin çocuklarına gösterdikleri davranışlar incelendiğinde, otoriter ve tutarsız tutumdan uzaklaştığı, demokratik ve aşırı koruyucu tutuma yaklaştığı belirlenmiştir. Bu sonuç, Kağıtçıbaşı'nın (1970, 1998) yaptığı araştırma bulguları ile uyuşmaktadır.

Anne-baba eğitimi grupları, anne baba tutumlarını ve çocukların benlik kavramlarını değiştirmede etkilidir. Tavormina (1980) ve Işık (1993) yaptıkları çalışmalarda bu sonucu desteklemektedir ve araştırma bulguları da bu çalışmanın bulgusuyla tutarlılık göstermektedir. 
Tablo 2.Empatik eğilim ölçeği deney ve kontrol gruplarına göre ön test ve son test ortalama puanların $t$-testi sonuçları

\begin{tabular}{|c|c|c|c|c|c|c|c|}
\hline \multirow{3}{*}{$\begin{array}{l}\text { Empatik } \\
\text { Eğilim } \\
\text { Ölçeği }\end{array}$} & \multicolumn{2}{|l|}{ Ön Test } & \multicolumn{5}{|c|}{ Son Test } \\
\hline & -_ & & _- & & & & \\
\hline & $\mathrm{x}$ & Ss & $\mathrm{x}$ & Ss & $\mathrm{sd}$ & $\mathrm{t}$ & $\mathrm{p}$ \\
\hline $\begin{array}{l}\text { Deney } \\
\text { (n:55) }\end{array}$ & 53,03 & 6,65 & 55,67 & 6,03 & 54 & $-2,58$ & ,012 \\
\hline $\begin{array}{l}\text { Kontrol } \\
(\mathrm{n}: 55)\end{array}$ & 51,34 & 6,48 & 51,25 & 8,51 & 54 & ,07 & 943 \\
\hline
\end{tabular}

$\mathrm{p}<0,001$

Tablo 2 incelendiğinde, “Anne Ev Ziyareti Eğitim Programı”na katılan annelerin son test EEÖ puanları programa katılmayan annelerin son test puanlarından anlamlı düzeyde bir artış gösterdiği bulunmuştur $(\mathrm{t}=-2,58$, $\mathrm{p}<, 001)$. Deney grubunda yer alan annelerin EEÖ puanlarının ortalaması ön testte 53,03 son testte 55,67 iken kontrol grubunda yer alan annelerin ön testte 51,34 son testte 51,25 olduğu anlaşılmaktadır. Deney grubundaki annelerin ön test ve son test puanları arasındaki farkın önemli olduğu görülmektedir $(\mathrm{p}<0,001)$.

Ünal (2003) okulöncesi çocuğu olan annelere "empatik iletişim eğitiminin" annelerin empatik becerileri düzeylerine etkisini incelemek amacıyla yaptığı deneysel çalışmada deney grubundaki annelerin eğitim sonucunda empatik becerilerinde istatistiksel olarak anlamlı bir gelişme görülmüştür. İzleme testinde de etkinin devam ettiği belirlenmiştir.

Uçmaz (2004) annelerin empatik beceri düzeyleri ile çocuk yetiştirme tutumları arasındaki ilişkiyi incelemiştir.Annelerin çocuk yetiştirme tutum ölçeği (PARI) den aldıkları puanlara göre empatik beceri düzeyi yüksek olan annelerin empatik beceri düzeyi düşük ve orta olanlara göre daha koruyucu ve disiplinli tutumda olduklarını göstermektedir.

$\mathrm{Bu}$ sonuçlar çalışmanın bulgusuyla tutarlılık göstermektedir.

\section{SONUÇ VE ÖNERILER}

$\mathrm{Bu}$ araştırmada annelere, anne baba tutumları ve çocuk üzerindeki etkileri, çocuğu etkili dinleme ve çocukla konuşma, çocukla iletişimleri ve sağlıksız iletişim kurmanın çocuk üzerindeki etkileri, çocukla oyun, cinsel eğitim, konularında güçlendirecek, bilgi, beceri ve farkındalık kazanmalarına 
yardımcı olabilecek yaşantılar geçirmelerini sağlayacak etkileşim ve yaşantıya dayalı olan ev ziyareti yöntemi ile bireysel eğitim programı oluşturulmuştur. Bu amaçla uygulanan "Anne Ev Ziyareti Eğitim Programı" ile annelerin olumlu davranışlarının sayısını artırmada, olumsuz davranışlarının sayısını azaltmada ve empatik eğilim düzeylerini artırmada etkili olup olmadığı deneysel olarak incelenmiştir.

Programa katılan kontrol grubundaki annelerin çocuklarına gösterdikleri davranışları incelendiğinde, önemli bir farklılık görülmezken deney grubundaki annelerin otoriter, aşırı koruyucu ve tutarsız tutumdan uzaklaştı̆ğ, demokratik ve koruyucu tutuma yaklaştığı belirlenmiştir. Ayrıca empatik eğilim düzeyleri açısından da kontrol grubundaki annelerde önemli bir artış görülmezken deney grubundaki annelerde anlamlı bir artış bulunmuştur.

Sonuç olarak uygulanan “Anne Ev Ziyareti Eğitim Programı”nın annelerin olumlu davranışlarının sayısını artırmada, olumsuz davranışlarının sayısını azaltmada ve empatik eğilim düzeylerini olumlu yönde artırmada etkili olduğu anlaşılmaktadır.

Araştırma bitiminde ortaya çıkan sonuçlar ışı̆̆ında öneriler şu şekilde olabilir.

Çocuğun yetiştirilmesinde, sevgi önemli bir kavramdır. Bu bakış açısıyla hareket edilmesi önemlidir. Anne-babalar, çocuklara demokratik bir ortam hazırlamalı, bu ortam içerisinde, olumlu davranışlar ön plana çıkarılmalıdır. Okulöncesi dönemdeki çocuğa yapabilecekleri yaptırılarak başarı duygusu tattırılıp ödüllendirilerek pekiştirilmelidir. Olumsuz davranışların açıklaması yapılmalı, nasıl davranılması gerektiği anlatılmalıdır. Anne-babaların söylemleri ile davranışları tutarlı olmalı, çocuğun gözünde model olduklarının bilincinde hareket etmelidirler. Çocuğun kendisiyle ilgili olumlu bir benlik geliştirmesi için bağımsız davranışları desteklenmeli, başkalarıyla kıyaslanmaktan kaçınılmalı, onun ayrı bir birey olduğunun bilinciyle hareket edilmelidir. Ayrıca çocuklarının gelişim dönemlerini ve bu dönemlerin özelliklerini bilmeli, çocuklarının tüm ihtiyaçlarına karşı duyarlı olmalıdırlar.

“Anne Ev Ziyareti Eğitim Programı" 10 hafta verilmiştir. Bu süreçten sonra belli aralıklarla izleme çalışmalarının yapılması uygun olacaktır. $\mathrm{Bu}$ çalışma sadece anneler ile yürütülmüştür, babaların da katılımı sağlanılarak program daha zenginleştirilebilir ya da babalar üzerindeki etkisinin incelenmesi anlamlı ve yerinde bir çalışma olacaktır. 


\section{KAYNAKLAR}

Arkonaç, A. S. (1998). Psikoloji zihin süreçleri bilimi. 2. Bask1, 284-293, 392-394, İstanbul: Alfa Basım Yayınevi.

Aytaç, S. (2000). Psikolojiye giriş: insanı anlama çabası. 1.Basım, 189-195. Bursa: Ezgi Kitabevi Yayınları.

Bayraktar,.(1998). Demokratik tutumun önemi,Okul ve Aile Dergisi, 6(1):41-43.

Baumrind, D., (1972) "Authoritarian v.s. Authoritative Parental Control" Adolescence, 3:255-272.

Baumgärtel, F., (1979) Hamburger Erziehungsverhaltensliste Für Mütter. Göttingen:Verlag für Psychologie, 6-24.

Craig,J.G.\&Kermis,D.M.(1995). Children Today.446,447, New Jersey:Prentice Hall Englewood Cliffs.

Darling, N. ve Steinberg, L., (1993) "Parenting Style as Context: Integrative Model" Psychological Bulletin, 113:487-496.

-Emci, Ö. L. (1995). Almanya'da yaşayan Türk ve Alman annelerin 3-6 yaş grubu bedensel ve zihinsel engelli çocuklarına yönelik eğitim davranışları. Yayınlanmamış yüksek lisans tezi. Ankara Üniversitesi, Sosyal Bilimler Enstitüsü, Ankara.

-Dökmen, Ü. (1994) İletişim Çatışmaları ve Empati, Sistem Yayıncılık, İstanbul.

Engler,B., (1981) Personality Theories: an Introduction. Houghton Mifflin Company, Boston.

Geçtan, Engin, (1981) Çağdaş Yaşam ve Normal Dışı Davranışlar. Üçüncü Basım, Maya Yayınları,Ankara.

Höder,J.(1992).Gesprächspsychotherapie, was sie kann,wie sie wirkt und wem sie hilft.Mannheim:Pal verlagsgesellschalf.

Işık,A.Z.(1993). İletişim Becerileri Konusunda Ebeveynlere verilen eğitimin iletişim çatışmalarına girme ĕgilimi üzerindeki etkisi. Yayınlanmamış yüksek lisans tezi. Marmara Üniversitesi, Sosyal Bilimler Enstitüsü, İstanbul.

Kağıtçıbaş1, Çiğdem, (1970) "Social Norms and Authoritarianism: A Turkish- American Comparison" Journal of Personality and Social Psychology, 16:444-451.

Kağıtçıbaşı, Çiğdem, (1998) "Üniversite Gençlerinin Algılanan Ana Baba Tutumları, Ana Babayla İlişkileri ve Bunların Bazı Kişilik Özellikleri İle Bağlantısı" Türk Psikoloji Dergisi, 9(32):15-25.

Kanigsberg, S.Joel ve Levant,F.Ronald, (1988) "Parental Attitudes and Children's Self-Concept and behaviour following Parents' Participation 
in Parent Training Groups" Journal of Community Psychology, 16, April, 152-160.

Kulaksızoğlu, Adnan, (1999) Ergenlik Psikolojisi, Remzi Kitapevi,113, İstanbul.

Kaya, Ö.(1994) Annelere verilen eğitimin çocuklarına karşı istenmedik tutumlarına etkisi. Yayınlanmamış yüksek lisans tezi. Gazi Üniversitesi, Sosyal Bilimler Enstitüsü, Ankara.

Maccoby, E.Eleanor (1984)"Socialization and Developmental Change" Child Development, 55, 2:317-328.

Öğretir, A.Dilek(2004) Pozitif Düşünceye Dayalı Ĕgitim Programının Annenin Kişilik Özelliğine Etkisi. Yayınlanmamış doktora tezi. Ankara Üniversitesi, Sosyal Bilimler Enstitüsü, Ankara.

Özdoğan, Berka, (1998) “Bilişsel Terapi” Türkiye'de Eğitim Yönetimi. Editörler:Haydar Taymaz ve Muhsin Hesapçıŏlu. İstanbul:Kültür koleji Eğitim Vakfı Yayınları,187.

Pardeck, T.J.\& Pardeck, A.J.(1988). Biblio therapy:A tool for helping preschool children deal with developmental change related to family relationship.Early Child Developmental and Care,47, 107-129.

Rogers,C., (1959) “A Theory of Therapy, Personality and Interpersonal Relationship as developed in Client-Centred Framework” In. Koch (ed) Psychology: A Study of a Science, 3,195.

Rosenthal,G.(1994).Gewalt und Erziehungsberatung prax kinderpsychol.KinderpsycRyder,V.(1995). Parents and their children.The Goodheart-Willcox Company,Inc.

Tausch, R.\& Tausch,M.A. (1981). Gesprächspsychotherapie.8.,Ergänzte Auflage.Verlag Für Psychologie, Göttingen.

Temel, Z.F.(1999). The study of the effect of mother-child education program. International school psychology association XXII annual coolquim theme and scientific program. Kreuzlingen/konstanz, Switzerland) Germany, July 30 Agust, 3:32.

Uçmaz, H.İ.(2004).Annelerin empatik beceri düzeyi ile çocuk yetiştirme tutumları arasındaki ilişkinin incelenmesi Yayınlanmamış tezi. Gazi Üniversitesi, Eğitim Bilimleri Enstitüsü, Ankara.

Ünal,F.(2003).Empatik iletişim eğiliminin okulöncesi çocuğu olan annelerin empatik beceri düzeylerine etkisi. Yayınlanmamış tezi. Gazi Üniversitesi, Sosyal Bilimler Enstitüsü, Ankara.

White S J(1997) Empath:A literature reviewed concept analysis, Journal of Clinical Nursing, 6:253-257. 
